\title{
THE EFFECT OF SEAM GEOMETRY ON PROPERTIES OF LASER WELDED NICKEL COATED STAINLESS STEEL STRIPES
}

\author{
Gábor Horváth ${ }^{1}$, Andor Körmöczi ${ }^{1}$, Tamás Szörényi ${ }^{1}$, Zsolt Geretovszky ${ }^{1}$ \\ ${ }^{1}$ University of Szeged, Department of Optics and Quantum Electronics, \\ H-6720 Szeged, Dóm tér 9., Hungary
}

\section{Introduction}

DOI: https://doi.org/10.14232/kvantumelektronika.9.14

In the $21^{\text {st }}$ century people finally realized that global warming is a real threat and started to introduce solutions that could protect and save our environment. One of these actions is trying to supply as much of the global energy needs from an electrical source instead of conventional fossil energy sources as possible. One of the most efficient ways for storing electrical energy is through battery cells. The batteries have different, but limited energy storing capacity, depending on their chemistry, and low power-to-weight ratio, in general [1]. As a result, to produce the required power for an electric motor capable of operating a vehicle, a large number of individual cells must be conjoined and integrated into a battery pack [2]. The photograph of a finished battery pack and the simplified scheme of its assembly levels are presented in Figure 1.

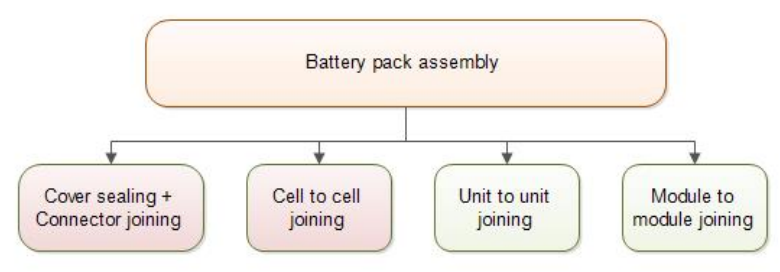

A)

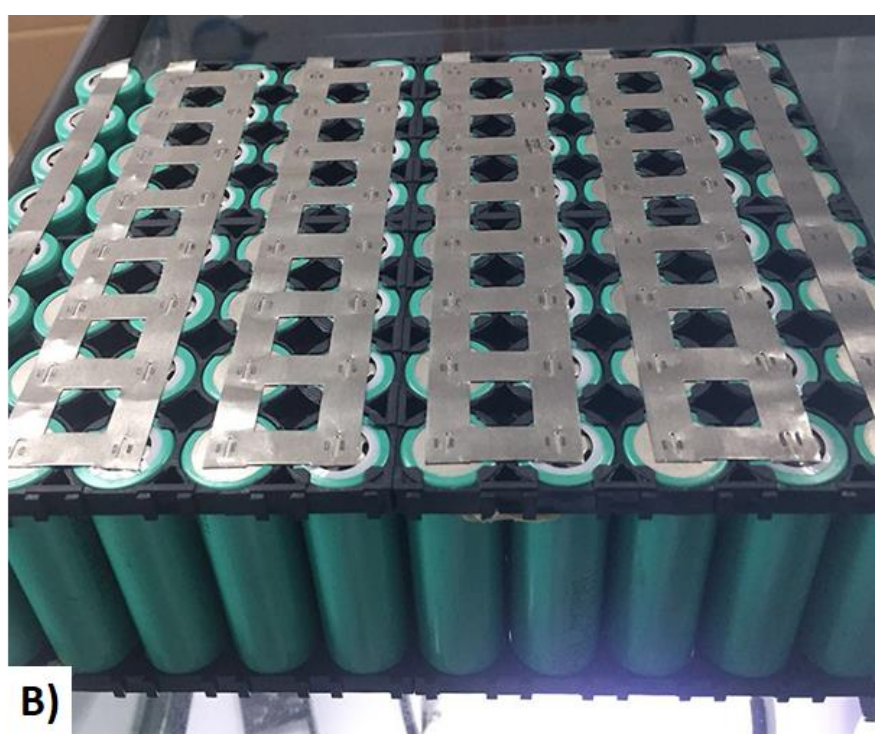

B)

Fig. 1. The assembly scheme (A) and a battery pack (B) [3]

The assembly of a battery pack is a multi-level process during which different types of permanent and non-permanent joining methods are used. As a rule of thumb, on the lower levels of the assembly, where a large number of connections have to be realized (the red boxes in Figure 1), a technique that offers excellent electrical and mechanical properties must be chosen. Welding in general serves as an excellent alternative here especially since certain forms of it are highly automatable as well [4, 5]. Laser (and sometimes ultrasonic) welding is a particularly preferred option for solving battery joining problems in the automotive industry $[5,6,7]$. This convention stems from the highly versatile nature of laser welding. When optimized well laser welded joints exhibit low electrical resistance, accompanied by high mechanical strength. Laser welding can be used for a variety of metal combinations with minimal target distortion as the laser beam is a non-contact "tool" and the heat affected zone can precisely be adjusted. The process is highly automatable, even up to a point where human intervention is not required $[4,5,8,9]$. Determining the perfect conditions for a particular 
welding problem can be deemed quite challenging as numerous laser and non-laser related parameters must be optimized [10].

In the following the behavior of the electrical and mechanical properties in relation to the changes made in the weld seam geometry will be discussed in detail.

\section{Experimental}

For our experiments, a tailor-made laser welding setup was built in which multiple laser parameters and complementary process conditions could be adjusted in an independent manner with high precision. The simplified view of the experimental setup can be seen in Figure 2.

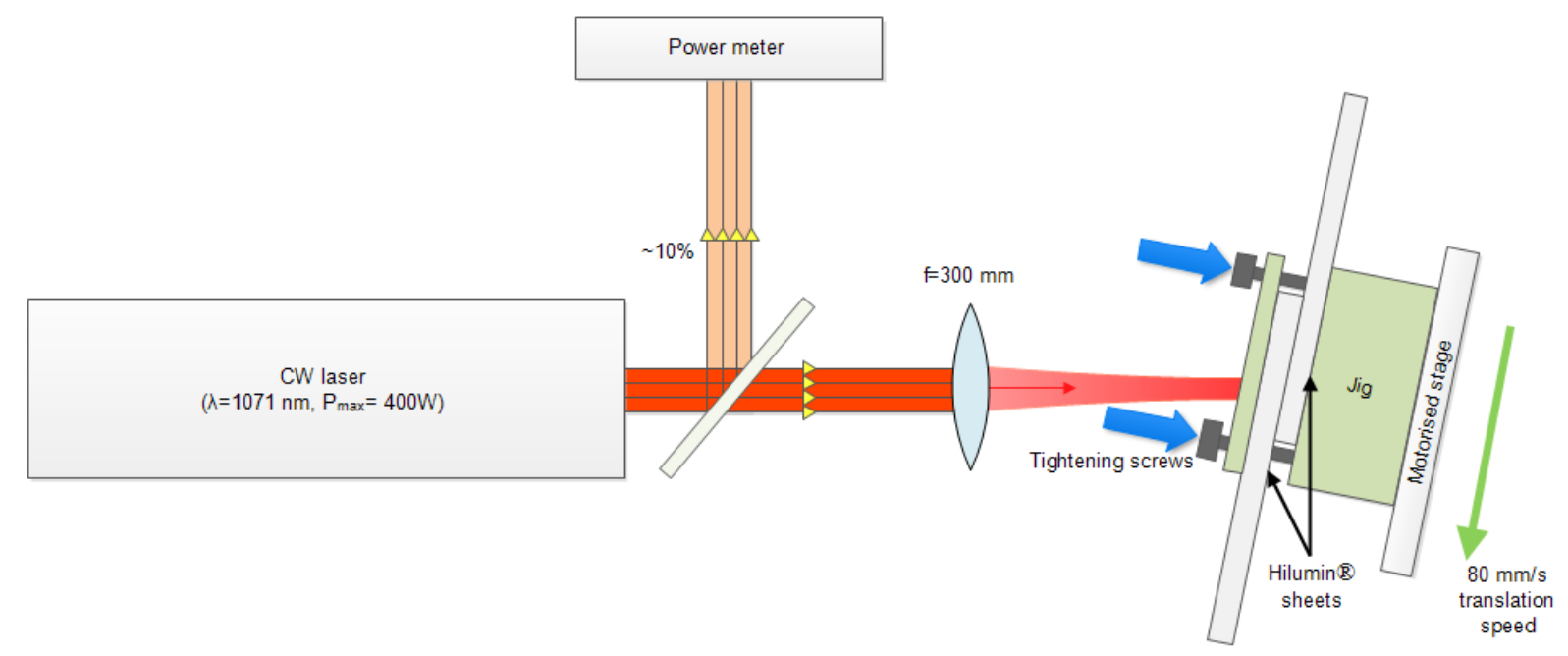

Fig. 2. The sketch of the experimental laser welding setup

An SPI SP-400C-0005 type Yb-doped, cw fiber laser (400 W maximum power, $1071 \mathrm{~nm}$ wavelength, single mode, non-polarized) was used as the core of the welding system. The laser beam was focused on the target surface using an N-BK7 glass, $300 \mathrm{~mm}$ focal length lens with anti-reflection coating (Thorlabs LA1484-B) resulting in $0.32 \mathrm{~mm}$ spot diameter. As target, a pair of $0.25 \mathrm{~mm}$ thick, $9 \mathrm{~mm}$ wide nickel coated (measured to be approx. $10 \mu \mathrm{m}$ layer on both sides) stainless steel (Hilumin $®$ ) sheets was used. The housing of battery cells is commonly made of Hilumin ${ }^{\circledR}$ therefore we used these samples as a model representation of the cap of the cell and the connecting stripe. The metal sheets were fastened in a custom-made jig and aligned at 10-degree angle relative to the laser beam to avoid back reflection. The jig was fixed to a programmable high-speed table (Allen Bradley Ultra 3000) that can operate in the $0-500 \mathrm{~mm} / \mathrm{s}$ speed range with high acceleration rate and velocity precision, during the experiments a constant $80 \mathrm{~mm} / \mathrm{s}$ speed was used. This setup allowed us to manufacture laser welded joints in lap configuration with high reproducibility.

For the mechanical testing of the laser welded samples a tensile tester machine (Tinius Olsen H5KT) was used. In order to gain tensile-shear strength values from the maximum force values measured by the tester machine, the bonding areas were determined by the analysis of microscope images of the weld area between the two metal sheets taken after fracturing, using an optical microscope (Olympus DSX510).

The measurement process of the electrical properties of the laser welded joints was slightly more challenging as no standardized method was available. This is due to the fact that the conductivity of welded joints in general is a rarely discussed subject. For our electrical measurements we chose to 
use a variant of the measurement method introduced by Schmidt et al. [11] and calculated the resistance of the welded samples along a fixed $21 \mathrm{~mm}$ length, incorporating the laser welded joint in its geometrical center. For the 4-point-probe measurements a desktop multimeter (Keithley 2401) was used to measure the voltage drop, while the current was provided by a power supply unit (TTi CPX200). The resistance values calculated from these measurements do not provide the joint resistance directly, they can however be used to derive tendencies and make comparisons in a standardized manner (e.g. fixed specimen thickness, width and measurement length).

\section{Results}

In our experiments we focused on changing the geometry of the weld seam while keeping the laser parameters constant and observed the effect of the changes on the joint's electrical and mechanical properties. During the experiments, the incident laser power was kept at $360 \mathrm{~W}$, the welding speed at $80 \mathrm{~mm} / \mathrm{s}$ with the processing laser beam focused to a spot diameter of $0.32 \mathrm{~mm}$. These parameters were chosen based on our previous, extended measurement results on seam morphology for this material. The detailed methodology of a similar morphological study on DC01 steel can be followed in one of our previous publication [12]. According to these results this set of laser parameters yielded a rather consistent single wave type, uniform weld bead with highly reproducible properties and stable joint area size that were pivotal for our present study.

When investigating the effects of changes in the geometry of the seam it was of great importance to keep the joint area constant. Accordingly, the length of the beads was chosen to keep the total area of each joint at $1.26 \mathrm{~mm}^{2}$. The actual values obtained for each pattern are depicted in Figure 3 with the average indicated by the horizontal orange line and the yellow zone representing the $95 \%$ confidence interval. Each bar represents the data average and the respective errors of 2 independent measurements.

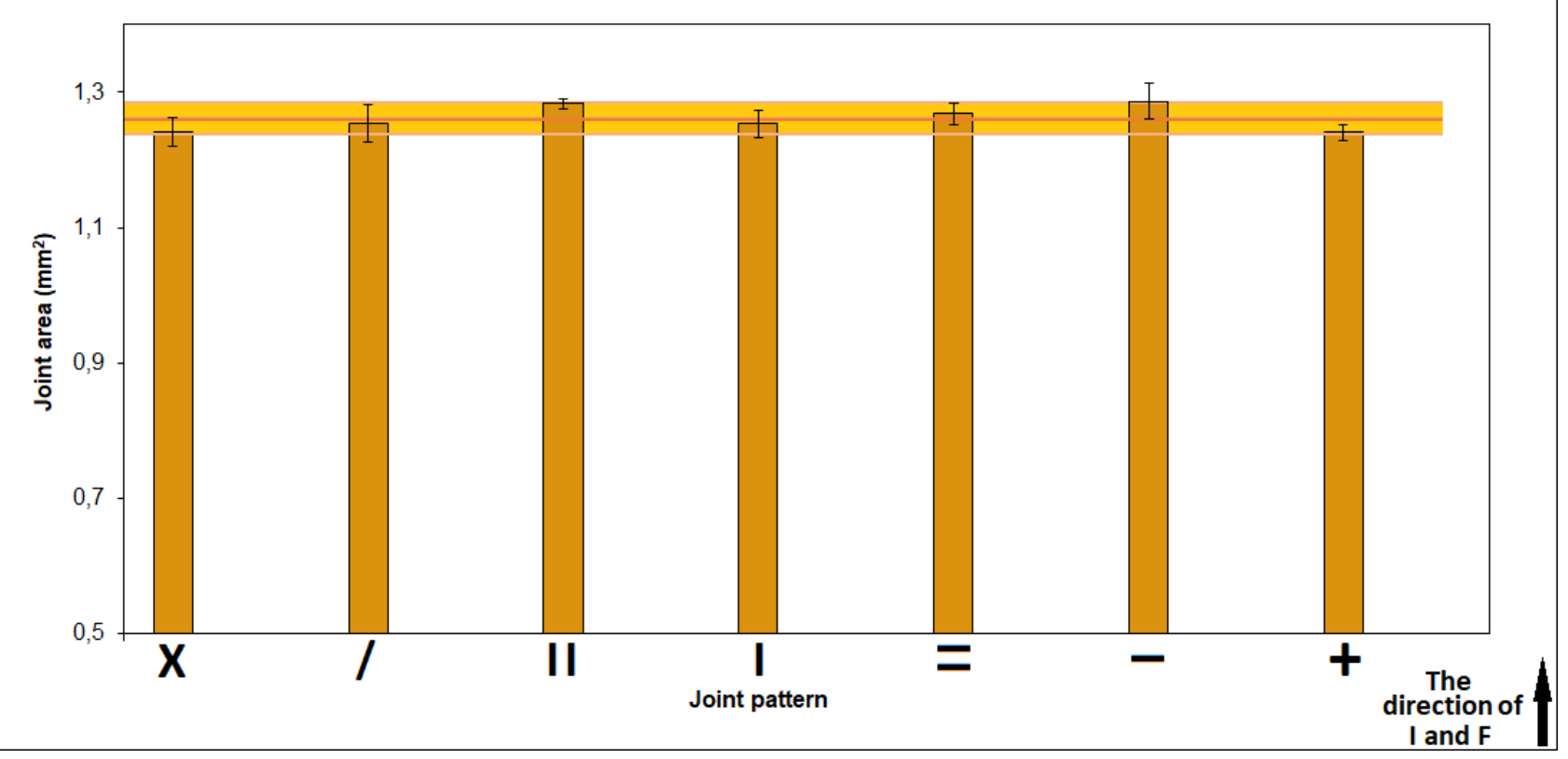

Fig. 3. The measured joint areas of the different weld seam geometries (the black arrow in the bottom right corner indicates the direction of the measuring current and force) $[360 \mathrm{~W}$ incident laser power, $80 \mathrm{~mm} / \mathrm{s}$ scanning speed, 
The symbols on the horizontal axis of Figure 3 indicate the shape and the bead contour's orientation relative to the measuring electrical current and testing force (being parallel to the vertical, Joint area axis of the graph). The black arrow in the bottom right corner of Figure 3 indicates the directions of the measuring electric current and the tensile force during testing. Every direction indicating term hereafter is relative to this fixed direction. In order to categorize the different seam geometry types, three distinct basic categories were introduced: double, quasi-double and single. The terminology "double" refers to seam geometries that consist of two independent, non-overlapping sections, "quasidouble" contours are made up from two straight lines that are interconnected through a junction and finally "single" refers to seams with a singular continuous form without bifurcations. As an example, the symbol " $\mid$ " means a single straight bead parallel to the measuring current and tensile force and a "=" symbol means a double bead perpendicular to it. The electrical and mechanical characteristics of the 7 weld seam geometries are shown in Figure 4 and 5 compared also to the ones of an unwelded Hilumin ${ }^{\circledR}$ base metal.

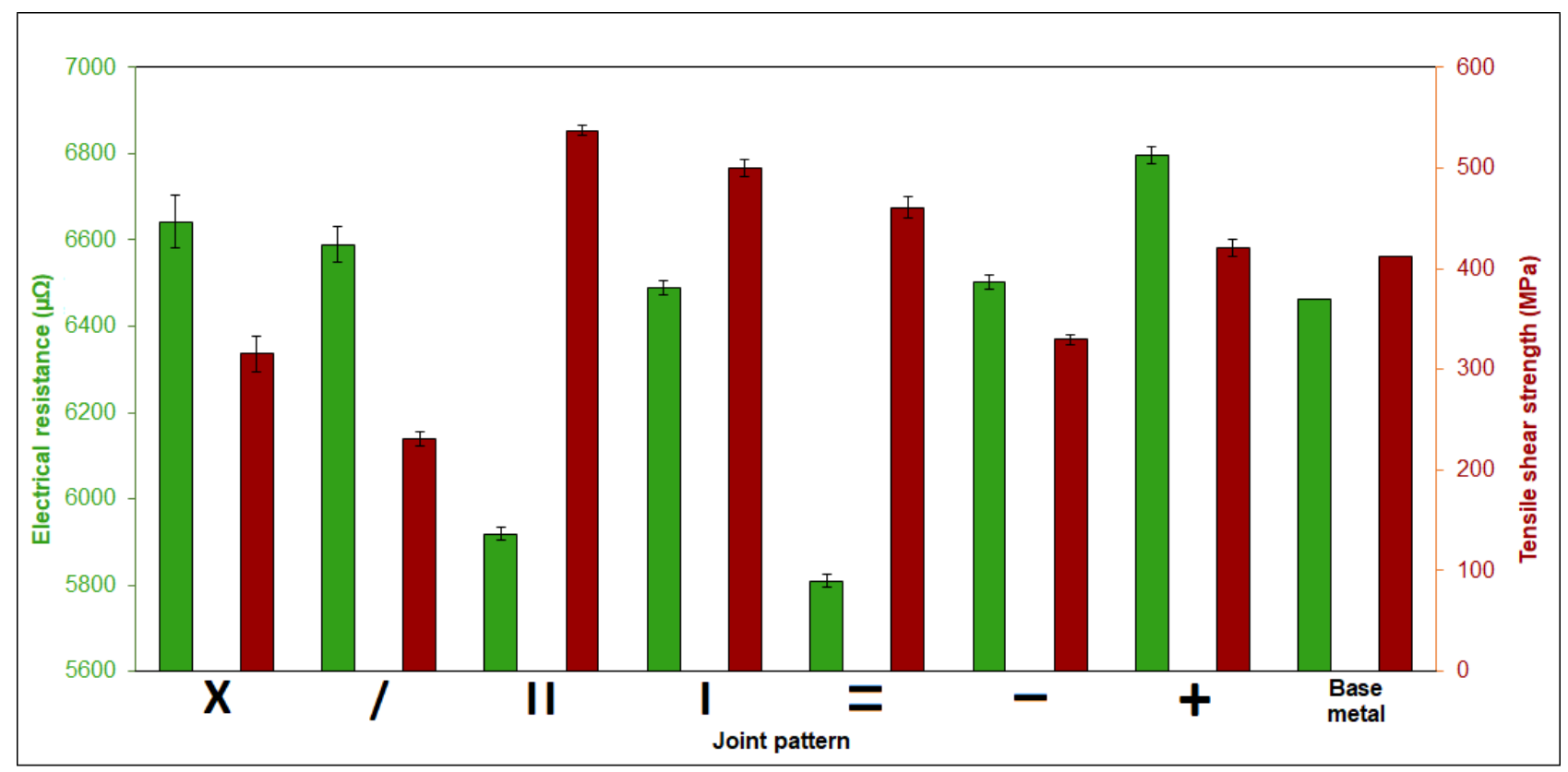

Fig. 4. The dependence of the electrical resistance and mechanical strength of the Hilumin® samples on the geometry of the weld seam [360W incident laser power, $80 \mathrm{~mm} / \mathrm{s}$ scanning speed, 0.32 laser spot diameter]

In Figure 5 the electrical resistance is swapped for electrical conductivity and plotted against mechanical strength to make a practically more relevant representation. As a result, the best joints in terms of both electrical and mechanical properties can be found in the upper right corner of Figure 5. 


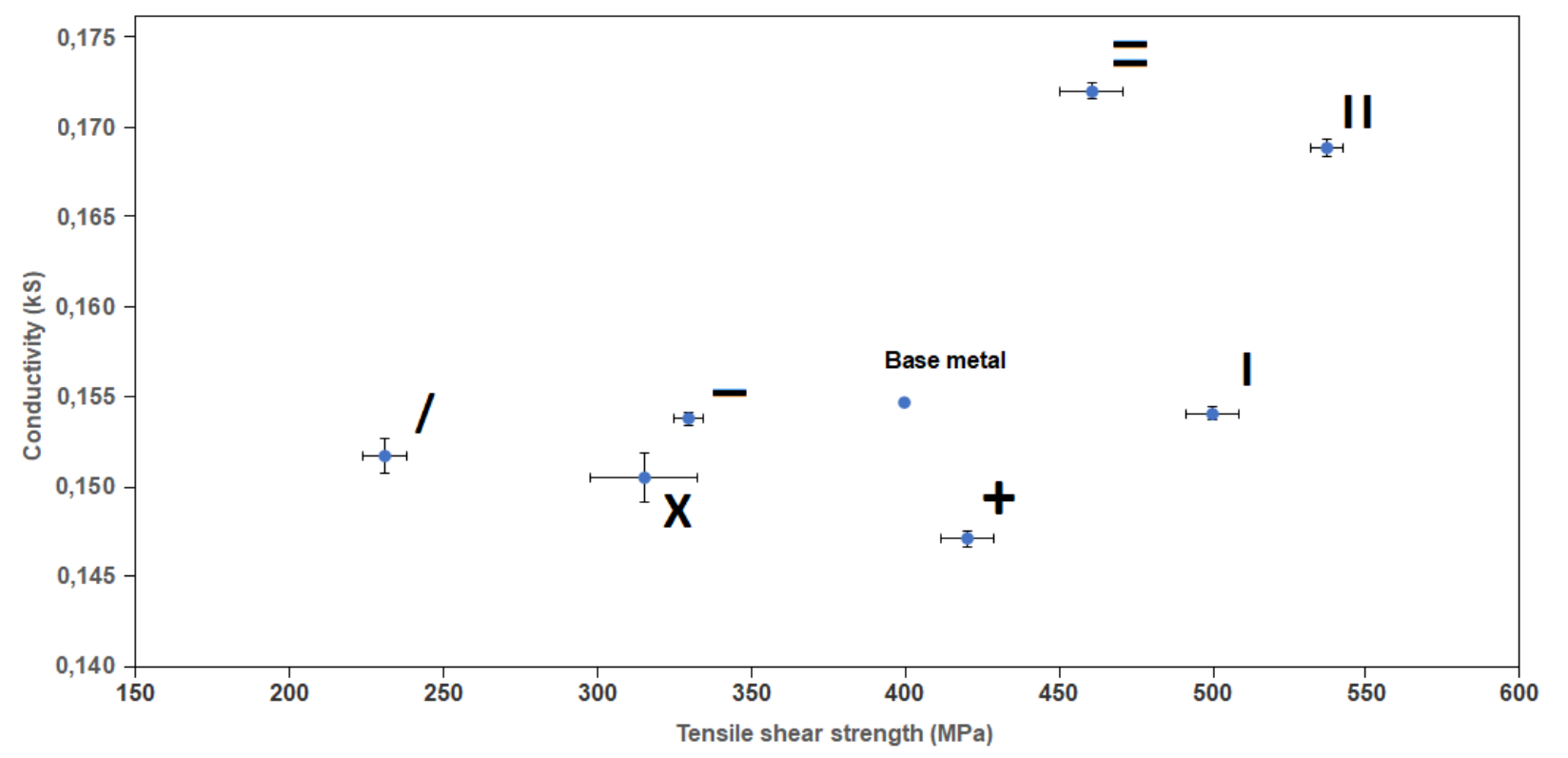

Fig. 5. The electrical conductivity as a function of the tensile shear strength of differently shaped laser welded joints [360W incident laser power, $80 \mathrm{~mm} / \mathrm{s}$ scanning speed, 0.32 laser spot diameter]

An important message of Figures 4 and 5 is that those patterns that consist of mostly parallel sections possess greater mechanical strength. As an example, when rotating the single perpendicular bead by 90 degrees the average mechanical strength rises from $329.9 \mathrm{MPa}$ to $500.1 \mathrm{MPa}$. This is in line with the expectations as a parallel section is affected by higher torque during the mechanical tests. The samples with double parallel beads have the best mechanical strength, namely 537.4 MPa.

In terms of electrical conductivity, the double perpendicular configuration seems to be the best with $0.172 \mathrm{kS}$. In general, shapes including two non-overlapping sections yield better electrical and, most of the time better mechanical properties. For instance, when using double joints instead of single ones the conductivity rises from $0.154 \mathrm{kS}$ to $0.168 \mathrm{kS}$, and from $0.153 \mathrm{kS}$ to $0.172 \mathrm{kS}$ in the parallel and perpendicular cases, respectively.

When considering the diagonal beads oriented 45-degree with respect to the axis of the current, they seem to possess worse electrical and mechanical properties when compared to the others. Using a quasi-double configuration of this version, the " $x$ " shape improves the mechanical, but decreases the conductive properties. When rotating this " $\times$ " shape and forming a "+" the mechanical strength rises further but the electrical conductivity falls. We also note that at this $1.26 \mathrm{~mm}^{2}$ joint area size the electrical properties of the base metal could not be surpassed when using a weld pattern without nonoverlapping sections.

The discussed experiments were also carried out on $0.5 \mathrm{~mm}$ thick non-coated DC01 steel stripes and the same tendencies were observed regardless of changing both the material and the thickness of the welded sheets, suggesting the universal nature of the tendencies, reported above.

\section{Conclusion}

In this paper we described the effect of a less frequently discussed laser welding process parameter, the weld seam geometry on the electrical and mechanical properties of the joint.

In brief, our results on the seam geometry in laser welding of nickel coated stainless steel stripes suggest, that the following conditions are beneficial for obtaining optimum weld performance: 
- The contour of the weld bead should consist of two non-overlapping sections.

- For optimum mechanical properties, seam geometries including sections mostly parallel to the measuring current and force are preferred.

- The double perpendicular bead configuration should always be applied when the electrical properties are of essence, as it drastically improves the electrical conductivity of the joint.

The observed tendencies apply not only on Hilumin ${ }^{\circledR}$, but on non-coated DC01 steel samples as well, substantiating the universality of our observations.

\section{Acknowledgements}

Our work is supported by the EFOP-3.6.1-16-2016-00014 project, entitled "Research and development of disruptive technologies in the area of e-mobility and their integration into the engineering education".

We would like to acknowledge Edutus University for providing the laser and some other supplementary equipment for our experiments.

\section{References}

[1] I. Gál, I. Jankovics, Gy. Bicsák, Á. Veress, J. Rohács, D. Rohács, Conceptual design of a small 4-seater aircraft with hybrid propulsion system, Innováció és Fenntartható Felszíni Közlekedés konferencia 2017 pp. 143-150. (2017)

[2] S. S. Lee, T. H. Kim, S. J. Hu, W. W. Cai, J. A. Abell, Joining technologies for automotive lithiumion battery manufacturing - A Review, ASME Proceedings Paper No. MSEC2010-34168, pp. 541549. (2010)

https://doi.org/10.1115/MSEC2010-34168

[3] https://www.szsunlaser.com/en/photo/dldchj.html (2020.11.25.)

[4] J. F. Ready, LIA Handbook of laser materials processing, (Magnolia Publishing, 2001)

[5] K. Ferjutz, J. R. Davis, ASM Handbook Vol. 6 Welding, brazing and soldering, (ASM International, 1993)

[6] M. J. Brand, P. A. Schmidt, M. F. Zaeh, A. Jossen, Welding techniques for battery cells and resulting electrical contact resistances, J. Energy Storage 1 pp. 7-14. (2015)

https://doi.org/10.1016/j.est.2015.04.001

[7] B. Mehlmanna, E. Gehlena, A. Olowinskya, A. Gillnera, Laser micro welding for ribbon bonding, Phys. Proc. 56 pp. 776-781. (2014)

https://doi.org/10.1016/j.phpro.2014.08.085

[8] C. Dawes, Laser welding - a practical guide, (Abington Publishing, 1992)

[9] S. Katayama, Handbook of laser welding technologies, (Woodhead Publishing, 2013)

[10] P. A. Schmidt, P. Schmitz, M. F. Zaeh, Laser beam welding of electrical contacts for the application in stationary energy, J. Laser Appl. 28 \#022423 (2016)

https://doi.org/10.2351/1.4943908 
[11] P. A. Schmidt, M. Schweier, M. F. Zaeh, Joining of lithium-ion batteries using laser beam welding: electrical losses of welded aluminum and copper joints, ICALEO 2012, Paper \#805 (2012) https://doi.org/10.2351/1.5062563

[12] G. Horváth; A. Körmöczi; T. Szörényi; Zs. Geretovszky, Laser welding and its implementation in the assembly of battery packs in aviation, International Journal of Sustainable Aviation Vol.6 No.1, pp. $51-65(2020)$

https://doi.org/10.1504/IJSA.2020.108094 